\title{
The economic security of power plants
}

\author{
Dorota Niedziółka ${ }^{1, *}$ and Pawet Czyżak ${ }^{2}$ \\ ${ }^{1}$ SGH Warsaw School of Economics Al. Niepodległości 164, 02-554 Warsaw, Poland \\ ${ }^{2}$ SGH Warsaw School of Economics Al. Niepodległości 164, 02-554 Warsaw, Poland
}

\begin{abstract}
Currently, power plants in Poland have to work in a very uncomfortable situation. Unstable market conditions and frequent changes in the law may have serious adverse consequences for their economic security. Power plants play a very important role in the economy. The effectiveness of their performance affects the activity of all other businesses. Therefore, it is very important to provide a definition of economic security for the power plants' sector and the factors determining its level. Maintaining economic security will allow energy generation companies to grow in a sustainable way as well as limit operational risk. A precise definition can also be used to create analytical tools for economic security measurement and monitoring. Proper usage of such tools can help energy generation companies sustain their economic security and properly plan their capital expenditures. The article focuses on the definition of economic security in the "micro" context of a separate business unit (enterprise). We also present an analytical model that measures economic security of a company engaged in the production of energy - a company of strategic importance for the national economy. The model uses macroeconomic variables, variables describing prices of raw material and legal / political stability in the country, as well as selected financial indicators. The appliance of conclusions resulting from the model's implementation will help provide economic security for companies generating energy.
\end{abstract}

\section{Introduction}

The issue of economic security is a new research field and is drawing more and more attention because of dynamic changes in the environment of enterprises. It is equally important to define the term of enterprise economic security, as well as identify the factors that lead to its achievement.

Until now, the term of power plant economic security was unknown. However, the processes of privatization and liberalization led to major changes in the perception of power plant safety and the risk that it faces [1]. Power plants are very specific business entities. Their size, measured through the number of employees ${ }^{2}$ and income ${ }^{3}$, and their role in the economy, defined by the amount of generated energy, installed power, market share, are of

\footnotetext{
*Corresponding author: dniedz@sgh.waw.pl

${ }^{2}$ In the PGE Group, employment in 2015 reached over 39 900, 44\% of which worked with conventional energy sources.

${ }^{3}$ The TAURON group had a sales income of 18375224000 PLN in 2015 [4].
} 
huge importance for the country and its government. At the same time, the possibility to invest in companies owning the power plants, the opening of the energy market, the realisation of new infrastructural investments, electricity trading, open the way to financial profit for potential investors and shareholders.

The electricity market differs greatly from other commodity markets, while also being very attractive. Therefore, it is essential to analyse the term of power plant economic security and the factors determining it. Providing a valid definition of economic security in the context of entities acting as energy producers is the main goal of this article. Also, it is equally important to point out factors that limit economic security and/or cause risk for the business entity. Such factors where proposed in the article and evaluated using a dedicated econometric model. The model was used to construct an analytical measure of economic security. Monitoring the value of this measure can help the business entity quickly respond to arising threats and sustain economic security at all times.

\section{The definition of economic security}

The state of security is equivalent to the lack of risk/threat. It is therefore a secondary term that evolved in a situation of immediate danger, or danger expected in the future [2]. Risk and fear became the foundations of security. Initially, security was defined in relation to social behaviour ${ }^{4}$. The security of an individual or a nation was of major interest for researchers, sociologists, historians. Security also had a military context and dimension. Political and military doctrines took into account the desirable state of political security, the achievement of which was based on satisfying several conditions: the integrity of the territory, the safety of the country's borders, the stability and durability of international agreements and military alliances.

The dynamics of political, economic and social changes caused an evolution in the meaning of security and broadened the research done in this field, especially in the second half of the 20th century. Globalization and the fusion of social and economic structures led to the increased significance of non-military security. Seeking the stability of an individual, new dimensions of security emerged: ecological security, energy security, information security and, finally, economic security. The need to define new areas of security is a result of increased and overwhelming uncertainty, as well as the complication and intensification of human relations with the environment, institutions and organizations. In the light of the modern World's accelerating evolution, questions arise regarding the means of providing peace and stability in all aspects of social and economic life.

The available research points out the many definitions of security, which are at the same time not precise and unclear. Such a broad spectrum of security perception introduces value for researchers. Defining security is used as a filter, enabling researchers to spot and analyse certain mechanisms, threats, risk or conditions of stability.

Economic security is a state, in which business entities have good conditions to realize their strategy and achieve their goals, e.g. increasing production, gaining market share, increasing stock prices, achieving financial liquidity, ensuring steady access to raw material [3]. The stability of the business entity's operations will be called the skill of limiting risk. The economic security of an enterprise should therefore be determined by the types of risk that the business entity will possibly be facing.

${ }^{4}$ That is why the term of security appears in the works of philosophers - A. Giddens, B. Russell, T. Hobbes. 


\section{Factors determining economic security of power plants}

In the case of power plants, the factors shaping economic security are strongly correlated with the characteristics of the energy sector. Typically, the power plants market is a closed market with few players. The most popular forms of market structure are monopoly and oligopoly. However, due to globalization causing a strong pressure for deregulation and privatization, the recent decades have introduced some structural changes [5]. This forced the existing market players to be involved in competition and rivalry. This unknown pressure is also caused by the emergence of new players, especially renewable energy companies, who may not be direct competitors for conventional power plants, but introduce additional risk on the market.

Power plants can therefore achieve economic security by limiting the risk linked to their specific market. Companies owning the power plants have knowledge about the characteristics of the market and possess tools that allow them to minimize threats. The ability to control risk and adapt to changes occurring in the entity's direct and indirect environment is strictly bound with the development of economic security.

The economic security of a power plant depends on the amount of produced energy, the market development perspectives, as well as the current energy policy. The economic growth is a measure of stability - a lack of threats that could endanger the production process. Assuming the world economic growth equal to $2.8 \%$ annually (up to 2040) and an increase in energy usage effectiveness by $35 \%$ (in the same timeframe), the demand for electricity will rise by about $1.3 \%$ annually [6]. The electricity demand projections influence the future energy production plans, the amount of installed power and investment projects carried out by power plant owners, both the refurbishment of current plants and the opening of new ones.

The presence of new business entities in the energy production market should not necessarily be treated as a threat, because the location of the power plant and the strong entry barriers can significantly limit competition on the local market [5]. It is worth remembering that power plants are treated as strategic entities in the economy. Their role is determined by the nation's level of economic development, the structure of the economy, especially the share of industry and services in GDP, and the effectiveness of energy production. Up to the 1970 s, energy markets were watched closely by the state - the energy market was treated not only as a determinant of social and economic development, but also as a strategic element of the country's security [5]. This type of market structure, with the domination of public ownership, limited the risk of a single entity's operations. Infrastructural investments were an essential part of the government's investment program and often had high priority. The energy prices were determined by administrative decrees. Energy markets were isolated, forming subsystems restricted to the country's borders. Only in the second half of the $20^{\text {th }}$ century, changes of different magnitude arose, concentrating on the privatization and deregulation of the energy sector. The introduced reforms changed the structure of the market - energy production was isolated from energy distribution. New entities appeared, focusing on energy trading. The spot market was introduced, access to electro-energetic networks has become common and the energy prices were freed ${ }^{5}$. In many countries, the market reforms introduced social disturbance, caused mainly by the fear of rising electricity prices. This fear involved not only households, but also enterprises, for which the rising electricity costs would translate into rising prices of offered goods and services. The decreasing economic security was also a consequence of limited access to investment project funding and the high costs of market transformation.

5 The character and level of introduced changes varied deeply - from widespread privatisation in the UK, to a public energy model in France and Germany [7] 
Currently, the economic security of power plants means that the entity can operate in the short term without significant threats (or with limited risk) in the following areas: location, raw material supply, financial situation, legal and market environment.

The evaluation of economic security in energy sector companies that produce electricity can be ambiguous. On one hand, combining energy providers with mining companies gives interesting synergy possibilities - access to own raw material for the power plant and steady demand for the coalmine. On the other hand, merging energy companies with mining companies limits investment abilities of the former. Power plants have to cut their investment budgets and move this money to help mines that are deeply in debt. Such a scenario can be judged negatively by stockholders and investors. Messages about future mergers have a strong impact on the stock price of an entity. Analysts usually have a negative opinion about state ownership in companies - this ownership can be used by the government to realize its targets at the cost of smaller stockholders.

A significant role in shaping the economic security of energy companies plays their financial situation. This includes the asset structure (ratio between fixed assets and current assets), asset rotation, investment policy, funding sources, capital level, equity and liabilities structure, stability of funding sources, cost of funding, timely debt payoff, cash flow (ability to pay, coverage of fixed assets with capital) and net results, EBITDA, net debt to EBITDA ratio.

Some major causes of uncertainty include a change in electricity demand, the decrease of energy price or sales margin. Such events can trigger a drop in stock prices of companies from the energy sector. This can further influence their relationship with commercial banks that will notice an increased risk of credit granting. Therefore, obtaining funding for current operations and the realization of investment projects can become difficult and more expensive.

The risk of doing business in the energy sector increases also when changes in energy and/or climate policy are announced [8]. Countries that are members of the European Union are committed to implement the common law. Limits of $\mathrm{CO}_{2}$ emission force changes in utilized energy sources or actions aimed at increasing production effectiveness and limiting emissions. These solutions compromise investment plans, increasing the expenses and causing pressure on energy prices. A change in energy prices is, however, negatively seen by the consumers and has a negative impact on the economy's competitiveness. The economic state of entities linked both vertically and horizontally is worsened.

At the same time, if the country does not meet its emission limits, funding from the so called 'renovation fund' - a support fund of the EU for countries that are making radical cuts in their $\mathrm{CO}_{2}$ emissions, can be suspended. What's more, crediting from foreign financial institutions can be withdrawn or limited. This has a strong negative impact on the financial stability of companies and their economic security.

The development of renewable energy can also be seen as a threat for conventional energy companies, since renewable energy companies have priority in accessing the distribution network. A 'merit order' mechanism is in place - old and expensive coal power plants are displaced with renewable energy plants, which have almost no variable costs and, therefore, have a higher position in the price ranking [9]. Renewable energy plants can be conquered by modern hard coal plants, which have around 30\% higher efficiency than currently used installations. The 'merit order' effect means that while more efficient installations (with lower variable costs - in Poland mainly costs of coal) enter the market, the energy prices decrease. The more energy is coming from 'cheaper' sources, the less energy from conventional plants is used.

An essential factor determining the power plant's economic security is access to raw material and its price. Energy groups having mines in their company portfolio are not affected by disturbances on the global supply market. They can also limit the risk of price changes. 
This aspect was strongly underlined in 2015 , when very low oil prices have strongly impacted the financial condition of energy resellers. Upstream companies had record-breaking profits, while downstream entities recorded losses. Low material prices raised questions about the profitability of oil extraction, many downstream companies considered selling extraction licenses and limiting the search for new sources. Also, the price of raw material determines the structure of utilized primary energy sources. Thus, decisions related to building new power plants have to take into account this aspect.

A different factor having impact on the level of economic security is the location of the power plant. The location of the energy production facility is usually determined based on several factors - access to water, demand market size, access to raw material. Location influences the costs of energy production. Risk increases when new power plants are localized close to existing ones - competition arises. Due to the integration of energy markets, decisions of investors in neighbouring countries should also be considered - a new power plant located next to the country's border and connected to the energy system can change the structure of offered electricity and weaken the position of the local energy producer. Concerns can also arise when, due to the realization of cross-border investment projects and new energy transportation channels, energy trade increases. Because of the abovementioned observations, it is becoming more often to evaluate investment projects not only within the borders of one country, but also taking into account the energy strategy of other countries in the region.

In the light of broadening the electricity supply, a question about the power market, its structure and size, arises [10]. The economic security of a power plant can increase as a result of the power market introduction - such a market would act as a guarantee of the country's energy security.

The level of economic security is also influenced strongly by the stability of the law. A more stable and long-term energy policy allows energy companies to operate in a steady environment. This aspect gains importance taking into account the characteristics of the energy infrastructure - its immobility, huge costs of investment projects and the long lifetime of its components. These characteristics do not allow the law to change rapidly and deeply. Adapting to legal changes is very costly and can strongly affect the financial stability of energy companies.

A summary of the factors described above is provided on Fig. 1. These factors will be used to propose an analytical measure of power plant economic security.

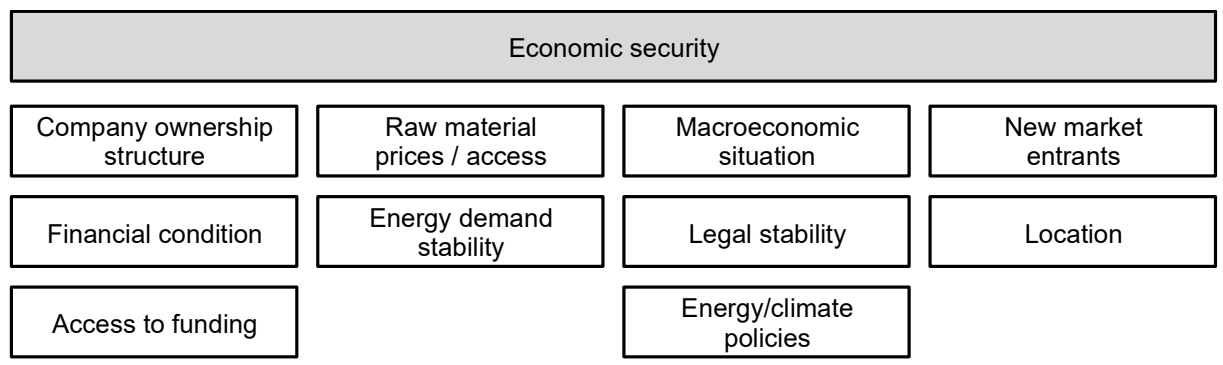

Fig. 1. Determinants of power plant economic security

\section{Analytical evaluation of power plant economic security}

In order to analyse factors determining the economic security of an energy production enterprise and measure the economic security objectively, a dedicated econometric model was prepared. The model utilized macroeconomic variables, financial indicators, coal price 
indices, political situation measures. The variables were chosen according to the factors outlined in the theoretical part of the article. As the dependent variable, the stock market price of Polska Grupa Energetyczna S. A. - the largest energy provider in Poland, was chosen. This is not an ideal measure of economic security, but the stock price indicates the moods of investors and their view on the risk a company is facing. The described model can be used to construct an objective measure of economic security of an energy production company.

Table 1. shows the explanatory variables included in the model. The variables were chosen from a larger pool of indicators from different groups, the choice was based on their statistical properties described further.

Table 1. Explanatory variables

\begin{tabular}{lll}
\hline Variable & Description & \multicolumn{1}{c}{ Expected dependency } \\
\hline WIG & $\begin{array}{l}\text { The value of the Warsaw } \\
\text { Stock Exchange Index }\end{array}$ & $\begin{array}{l}\text { Positive (a general increase in the investors moods } \\
\text { should result in the increase of stock prices of } \\
\text { specific companies) }\end{array}$ \\
CPI & $\begin{array}{l}\text { Consumer price index for } \\
\text { Poland } \\
\text { [last month = 100] }\end{array}$ & $\begin{array}{l}\text { Negative in the long term, Positive in the short } \\
\text { term (an increasing inflation can increase the } \\
\text { company's profit, but in the long term it usually is } \\
\text { a sign of macroeconomic problems in the country) }\end{array}$ \\
EURPLN & EUR/PLN exchange rate & $\begin{array}{l}\text { Negative (an increase in the exchange rate can } \\
\text { increase the costs of imported raw material, the } \\
\text { rate change can also be an effect of } \\
\text { macroeconomic problems) }\end{array}$ \\
RB_Index & $\begin{array}{l}\text { Coal prices in Richard's } \\
\text { Bay (South Africa) [USD] }\end{array}$ & $\begin{array}{l}\text { Negative (declining coal prices have a positive } \\
\text { effect on the margin of an energy producer) }\end{array}$ \\
DEBT_EBID & $\begin{array}{l}\text { Net debt / EBITDA for } \\
\text { PGE S.A. }\end{array}$ & $\begin{array}{l}\text { Negative in the long term (debt increase is usually } \\
\text { interpreted as a signal of financial problems of a } \\
\text { company) }\end{array}$ \\
TA_PGE & Political / Legal stability indicators \\
\hline Legal_Acts & $\begin{array}{l}\text { Number of signed legal } \\
\text { acts }\end{array}$ & $\begin{array}{l}\text { Negative (changes in regulations and bureaucracy } \\
\text { are significant risks for an energy production } \\
\text { company) }\end{array}$ \\
\hline
\end{tabular}

Monthly data from 12.2009 to 03.2016 was used, the data sources included: World Bank, GUS (Polish Statistical Office), NBP (Polish National Bank), PGE financial reports, biznesradar.pl and wnp.pl data aggregators. The DEBT_EBITDA_PGE variable was extracted from quarterly data using spline interpolation. All variables were transformed by a logarithmic function to enhance their statistical properties (exclude heteroscedasticity).

Based on visual analysis, most variables used in the model show a significant trend - such a situation is typical for non-stationary processes (processes which distribution changes in time) [11]. Stationarity can be measured analytically using the Augmented Dickey-Fuller procedure [12], in which a $y_{t}=\alpha y_{t-1}+\varepsilon_{t}$ model is estimated repeatedly for subsequent differences until the $\mathrm{H}_{0}: \alpha<1$ hypothesis is rejected. The so-called integration level marks the number of differentiations that have to be performed to transpose the process to stationarity. Testing for stationarity is important since non-stationary processes require special econometric treatment, such as cointegration methods. Variables are cointegrated, if a stationary linear combination of them exists. To test the existence of cointegration, the 
Johansen procedure can be used [13]. The Johansen test is repeated for subsequent ranks of cointegration - accepting the $\mathrm{H}_{0}$ for the given rank means that this rank is the rank of cointegration. If the $\mathrm{H}_{0}$ is declined, the cointegration rank is higher than the current rank and the test should be repeated (up to the moment when $\mathrm{H}_{0}$ is accepted). If the existence of cointegration is confirmed, a vector error correction mechanism (VECM) can be used. A VECM is an extension to a vector autoregression model (VAR) - contains an additional error term that can be used for analysing long-term dependencies between variables. The VECM has similar features as a VAR - its stability, residual distribution, autocorrelation should be tested to check if the model is correct. It is also important to properly choose the lag order this can be done using information criteria such as BIC, AIC, HQ.

According to the methodology described above, the first step of the model's construction included ADF stationarity tests. The optimum lag was chosen using AIC criteria, testing down from 11. The results are presented in Table 2. All variables except EURPLN are clearly non-stationary and 1-st order integrated, EURPLN becomes 1-st order integrated if a 5\% threshold is chosen, otherwise it seems to be stationary.

Table 2. ADF test results

\begin{tabular}{|c|c|c|}
\hline Variable & $\begin{array}{l}\text { p-value for model with } \\
\text { constant value }\end{array}$ & $\begin{array}{l}\text { p-value for model with constant value } \\
\text { and linear trend }\end{array}$ \\
\hline I PGE & 0.2 & 0.4757 \\
\hline I_WIG & 0.2763 & 0.4442 \\
\hline I_CPI & 0.8939 & 0.2827 \\
\hline I_EUR_PLN & 0.06536 & 0.05917 \\
\hline I RBIndex & 0.9314 & 0.2229 \\
\hline I DEBT EBIDTA PGE & 0.3252 & 0.2734 \\
\hline I-LegalĀets & 0.9775 & 0.9853 \\
\hline Al & $4.731 \mathrm{e}-07$ & \\
\hline$\Delta I+W I G$ & $1.666 \mathrm{e}-07$ & \\
\hline DI_CPI & $2.094 \mathrm{e}-09$ & \\
\hline Al_EUR_PLN & $1.548 \mathrm{e}-07$ & \\
\hline$\Delta$ I_RBIndex & $1.031 \mathrm{e}-07$ & \\
\hline AI_DEBT_EBIDTA_PGE & 0.03306 & \\
\hline$\Delta \mathrm{l} \_$LegalActs & 0.001924 & \\
\hline
\end{tabular}

Since the variables are non-stationary, their analysis can either be carried out through the use of cointegration methods, or by differentiating the variables to ensure their stationarity and then using a standard VAR model. Therefore, a Johansen cointegration test was performed with an unconstrained constant and linear cointegration trend setting. The optimum lag of 7 was chosen using AIC, BIC and HQC information criteria (the test is performed for a n-1 lag order). The results of the Johansen test indicate, that 3 cointegration relations exist in the model ( $\mathrm{p}$-value for rank 3 path test $=0,0528, \mathrm{~L}_{\max }$ test $=0,1216$ ).

Because a cointegration relation exists, a VECM could be created. The lag order was set to 7 , the cointegration rank to 3 , deterministic factors as in the Johansen test. The estimation results are correct, with most of the alpha values being between 1 and -1 (the system should return to equilibrium / the error correction mechanism should work properly). The model was tested for its correctness (Table. 3) - no residuals autocorrelation or ARCH effects were found, the normality of the residuals distribution was confirmed. 
Table 3. VECM correctness tests

\begin{tabular}{llll}
\hline Variable & $\begin{array}{l}\text { p-value for residual } \\
\text { autocorrelation test } \\
\text { (H0: autocorrelation } \\
\text { does not exist) }\end{array}$ & $\begin{array}{l}\text { p-value for ARCH } \\
\text { effects test } \\
\text { (H0: ARCH effects } \\
\text { do not exist) }\end{array}$ & $\begin{array}{l}\text { p-value for residual } \\
\text { normality } \\
\text { (H0: residuals have } \\
\text { a normal } \\
\text { distribution) }\end{array}$ \\
\hline I_PGE & 0.961 & 0.460088 & 0.9738 \\
I_WIG & 0.897 & 0.427474 & \\
I_CPI & 0.978 & 0.768965 \\
I_EURPLN & 0.936 & 0.544592 & \\
I_RBIndex & 0.763 & 0.7929 & \\
I_DEBT_EBITDA_PGE & 0.819 & 0.357016 & \\
\hline I_LegalActs & 0.224 & 0.826473 & \\
\hline
\end{tabular}

The system is stable - all unit roots are inside the unity circle, with the roots related to cointegration relations being on the unity circle. The impulse response charts on Fig. 2 indicate the temporal behaviour of 1_PKB in response to a peak change in the explanatory variables
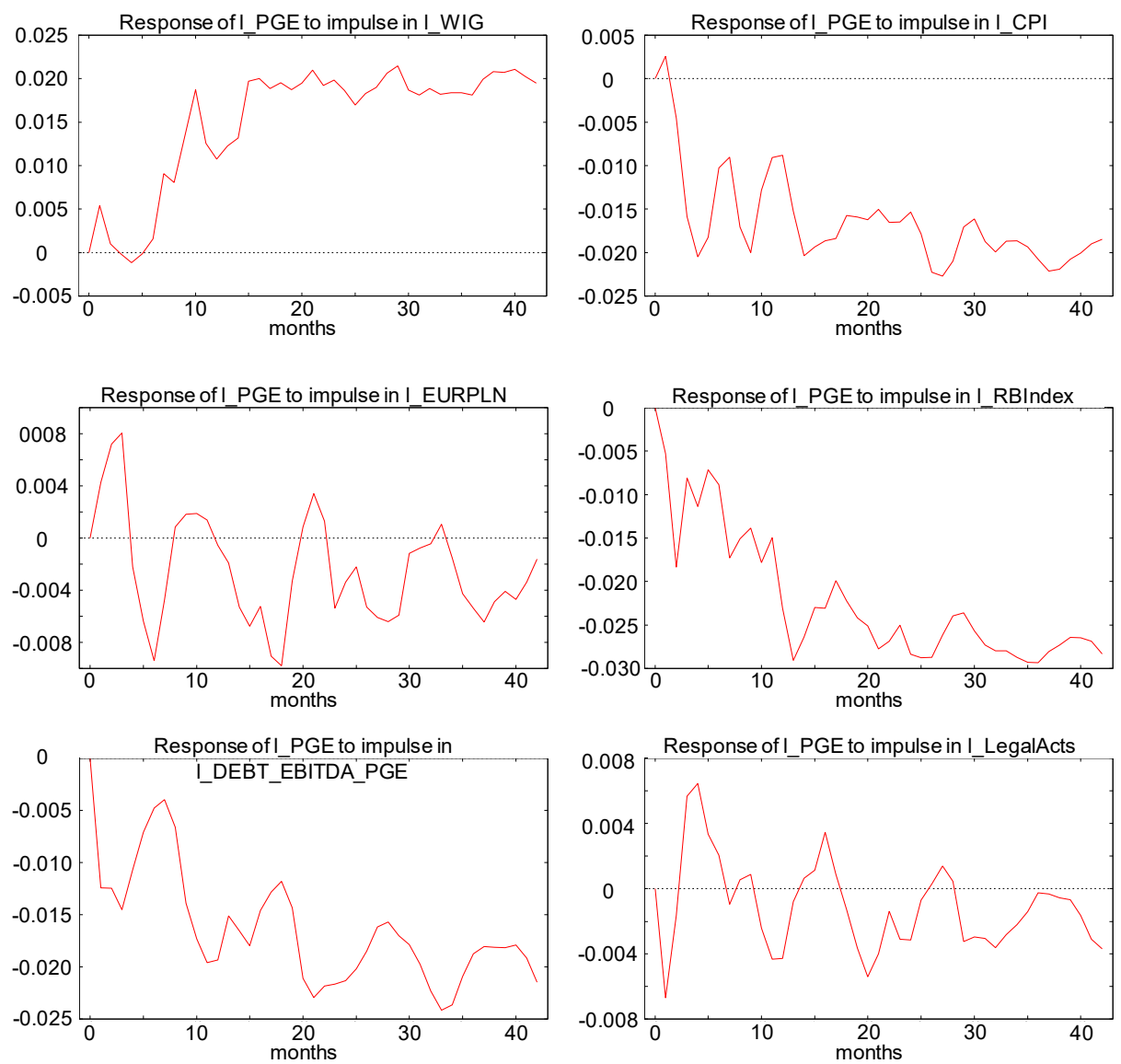

Fig. 2. Impulse response functions

Responding to an impulse in 1_WIG, 1_PGE increases in the first month and stabilizes on a positive value after around 15 months. This matches the expectations - the increase in 
general moods on the stock exchange has a positive impact on the prices of specific companies and their economic security. After an increase in 1_CPI / inflation, 1_PGE increases in the first month and stabilizes on a negative value after around 15 months. This also matches the expected behaviour - the increase in energy prices can temporarily increase the incomes and signify an increased economic growth. However, in the long term, the rising inflation has a negative impact on the economy and the economic security of companies. The change in EURPLN causes a significant increase in PGE in the first three months, but then the value oscillates around a negative number. The short-term increase can be caused by better conditions for energy or coal export from Poland to the EU. However, in the long term, the stronger EUR increases costs of coal import and can be a signal of macroeconomic problems in Poland, both factors having a negative effect on economic security. A positive impulse in RB_Index causes a systematic decrease in PGE, with a steady negative value reached after 20 months. This matches the expectations - the increase of coal prices increases costs and decreases margins, threatening the economic security. As indicated by the impulse response to a change in DEBT_EBITDA_PGE, increased debt also decreases the stock price and threatens the economic security - the impulse response function is clearly negative. The response to Legal_Acts is not clear, oscillating around a small negative value after significant (but declining in amplitude) increases and decreases. This behaviour could indicate a nonoptimal choice of the explanatory variable - the increased number of introduced legal acts can be linked to increased burocracy, but also to positive changes in the current law. An optimum choice of a variable indicating the political and legal situation of a country, with a monthly frequency, is very difficult and will be the topic of further analysis in future publications. Generally, the impulse responses match the expectations, confirming the correct construction of the model.

Below, the variance decomposition chart is shown (Fig. 3a). The chart indicates that the error is determined mainly by lags of the dependent variable. This is correct for this model, since the explanatory variables were not chosen for forecasting purposes, but to isolate factors influencing economic security. According to Fig. 3a, in the short and mid-term, the company's debt and raw material prices have the biggest influence on its economic security. In a longer term, the inflation increases in significance, indicating the change in macroeconomic conditions. In the long term, coal prices remain the most significant factor of economic security. However, also 1_WIG appears to increase in significance - stock behaviour is an important measure of the consumer trends and economic stability in the country and has an influence on the economic security of the company. Low significance can be attributed to exchange rates and legal situation. In Poland, most of the utilized coal is taken mainly from local sources so the exchange rates do not influence raw material costs. The low significance of legal factors results probably from a non-optimum choice of the explanatory variable - changes in energy law potentially can have a huge impact on the economic security of PGE.
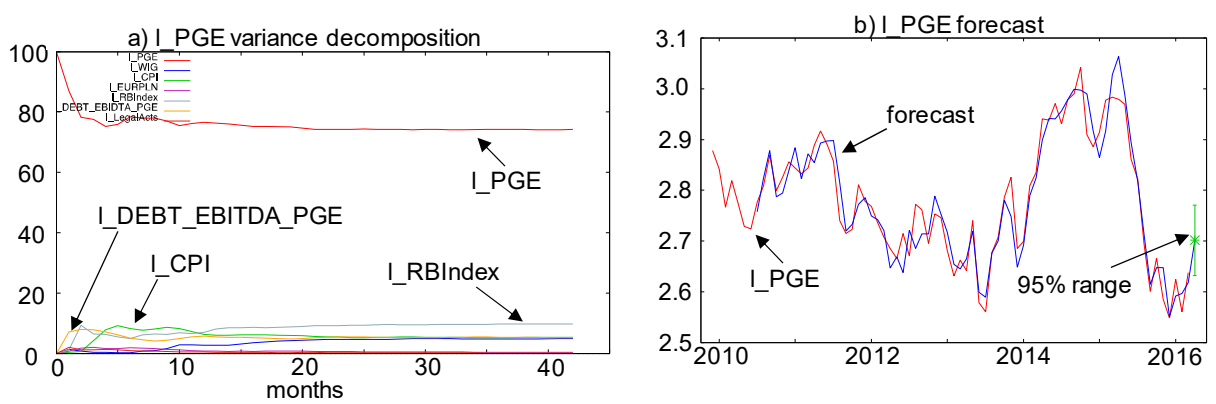

Fig. 3. Variance decomposition (a) and forecast (b) for 1_PGE 
Fig. $3 \mathrm{~b}$ shows the original values for PGE stock prices and a forecast created using the VECM model. Even though the model was not optimized for stock price forecasting, the matching is quite good. Static in-sample forecasting was used (forecast for each observation is calculated from real values from previous periods, not from previous forecasts). Low error values (mean absolute percentage error around 1\%) indicate that the model could be successfully used in forecasting, especially after further optimization for this purpose.

\section{Conclusions}

Energy companies are currently under huge pressure because of changes in the political, economical and legal setting, which strongly impacts their operations. This situation is a result of the energy market opening and the evolution of free market mechanisms, backed by the introduction of foreign capital. Strong vertical and horizontal connections and the national and international environment, push energy companies to seek new ways of achieving economic security. Though the state of economic security is not permanent, striving for its achievement gives business entities the possibility to limit risk. Sustaining economic security is possible using the analytical tools described in the paper, particularly monitoring the value of the proposed measures. Our research shows that the most significant factors shaping the economic security of an energy company are: raw material prices, the financial condition of the entity and macroeconomic conditions. Surely, the political and legal situation in the region is also a crucial aspect of economic security, however, it is very difficult to provide an adequate analytical measure in this field.

\section{References}

1. M. Zerka, Polskie Sieci Elektroenergetyczne S.A., web source: http://www.cire.pl/publikacje/Art_Zerka.pdf (November 2016)

2. U. Beck, Spoteczeństwo Ryzyka (W̄yd. Naukowe Scholar, Warsaw, 2004)

3. Y. Shutyak, O. Danylenko, D. Van Caillie, Conf. Proc. REDETE 2014, web source: https://ssrn.com/abstract=2640291 (November 2016)

4. web source: https://www.tauron.pl/tauron/grupa-tauron/tauron-wliczbach/Strony/tauron-w-liczbach.aspx (August 2016)

5. D. Niedziółka, Rynek Energii w Polsce (Wyd. Difin, Warsaw, 2010)

6. Statoil's Energy Perspectives 2013, web source: http://www.statoil.com/en/ NewsAndMedia/News/2013/Pages/14Jun_EnergyPerspectives.aspx (August 2016)

7. T. Jamab, M. Pollitt, Energy J., Spec. Issue on Euro. Elec. Liberal., p. 11-41, (2005)

8. B. Knopf, P. Nahmmacher, E. Schmid, Energy Policy, 85, p. 50-60, (2015)

9. F. Sensfuß, M. Ragwitz, M. Genoese, Work. Pap. Sust. and Innov., no. 7 (2007)

10. E. Bayer, W. Kukuła, J. Rączka, M. Stoczkiewicz, Założenia rynku mocy w Polsce analiza prawna i ekonomiczna, (ClientEarth, Warsaw, 2016)

11. C.R. Nelson, C. R. Plosser, J. Monetary Econ., 10(2), p. 139-162, (1982)

12. D. A. Dickey, W. A. Fuller, J. Amer. Stat. Assoc., 74(366), p. 427-431, (1979)

13. S. Johansen, Econometrica, 59(6), p.1551-1580, (1991)

14. The IEA Model of Short-term Energy Security (MOSES) Primary Energy Sources and Secondary Fuels, International Energy Agency

15. Ch. Winzer Conceptualizing Energy Security, EPRG Working Paper 1123 Cambridge Working Paper in Economics 1151 